\title{
Evolutionary opportunity and the limits of community similarity in replicate radiations of island lizards
}

\author{
Luke Frishkoff ${ }^{1}$, Gavia Lertzman-Lepofsky² , and D. Luke Mahler ${ }^{2}$ \\ ${ }^{1}$ The University of Texas at Arlington \\ ${ }^{2}$ University of Toronto
}

February 14, 2022

\begin{abstract}
Ecological community structure ultimately depends on evolution producing community members. To understand how macroevolutionary processes shape communities, we surveyed Anolis lizard assemblages across elevations on Jamaica and Hispaniola, neighboring Caribbean islands similar in environment, but contrasting in evolutionary richness. The impact of diversification on local communities depends on available opportunities for speciation within or between ecologically distinct sub-regions. Where opportunities abound, as in the vast lowlands of both islands, communities converge in species richness and average morphology. But community structures diverge in the highlands. On Jamaica, where limited highland area restricted diversification, communities remain depauperate and consist largely of elevational generalists. In contrast, a unique fauna of high-elevation specialists evolved in the expansive Hispaniolan highlands, augmenting highland richness, and driving islandwide turnover in community composition. Accounting for disparate evolutionary opportunities may illuminate when regional diversity will enhance local diversity and help identify the causes of convergent versus divergent community structure.
\end{abstract}

Title:

Evolutionary opportunity and the limits of community similarity in replicate radiations of island lizards

Authors:

Luke Owen Frishkoff $^{1 a}$, Gavia Lertzman-Lepofsky ${ }^{2 b}$, D. Luke Mahler ${ }^{2 c}$

1. University of Texas at Arlington

2. University of Toronto

a. luke.frishkoff@uta.edu

b. gavia.lertzmanlepofsky@mail.utoronto.ca

c. luke.mahler@utoronto.ca

Statement of authorship: LOF and DLM designed the study, collected the data, and wrote the first draft of the manuscript, LOF analyzed the data with contributions from GLL, and all authors contributed to revisions.

Data accessibility statement: Should the manuscript be accepted, the data supporting the results will be archived in the Figshare repository and the data DOI will be included at the end of the article.

Running title: Macroevolution and community similarity

Key words: 
Anolis, Macroevolution, Adaptive radiation, Biogeography, Community structure, Local versus regional richness, Beta-diversity, Ecological limits, Elevation, Species pools

Article type: Letter

Word count abstract: 150

Word count maintext: 4,997

Reference count: 71

Number of figures: 4

Number of tables: 1

Corresponding Author:

Luke Frishkoff

luke.frishkoff@uta.edu

541-972-6006

\begin{abstract}
Ecological community structure ultimately depends on evolution producing community members. To understand how macroevolutionary processes shape communities, we surveyed Anolis lizard assemblages across elevations on Jamaica and Hispaniola, neighboring Caribbean islands similar in environment, but contrasting in evolutionary richness. The impact of diversification on local communities depends on available opportunities for speciation within or between ecologically distinct sub-regions. Where opportunities abound, as in the vast lowlands of both islands, communities converge in species richness and average morphology. But community structures diverge in the highlands. On Jamaica, where limited highland area restricted diversification, communities remain depauperate and consist largely of elevational generalists. In contrast, a unique fauna of high-elevation specialists evolved in the expansive Hispaniolan highlands, augmenting highland richness, and driving islandwide turnover in community composition. Accounting for disparate evolutionary opportunities may illuminate when regional diversity will enhance local diversity and help identify the causes of convergent versus divergent community structure.
\end{abstract}

\title{
Introduction
}

A central goal in ecology is to determine what forces structure local communities, and to understand why community membership varies across space. According to theory, the composition of local communities reflects a balance between regional inputs, via speciation and dispersal, and local controls, such as environmental filtering and competition (MacArthur \& Wilson 1967; Rosenzweig 1995; Vellend 2016; Leibold \& Chase 2018). If local forces control diversity equilibria, communities in similar environments are expected to be similar in composition, regardless of the size of their regional species pools; conversely, if regional forces predominate, regions with more species should also possess greater local diversity (Ricklefs 1987). Debate over whether local or regional forces dominate has reached an uneasy détente, as macroecological patterns suggest local control in some systems, and pervasive regional influences in others (Ricklefs \& Schluter 1994; Myers et al. 2013; Cornell \& Harrison 2014). What is thus crucial is to identify the reasons for this variation in controls of local diversity, and to establish a framework to explain why one system's local diversity is set by local processes, while another's reflects inputs from the regional species pool (Cornell 1999; Harrison \& Cornell 2008; Lessard et al. 2012).

We approach this challenge by focusing on a pair of linked mechanisms by which macroevolutionary inputs could ultimately determine community structure. First, we consider the attributes of biogeographic landscapes that foster (or limit) the evolution of diverse regional species pools (McPeek \& Brown 2000; Swenson 2011; Zobel et al. 2011; Mittelbach \& Schemske 2015; Craven et al. 2019). Second, we consider how these richer regional species pools could then lead to saturated communities (competition-structured communities 
where richness reaches a stable equilibrium; Rabosky \& Hurlbert 2015; Storch \& Okie 2019). Crucially, species pools are generated by an interplay of ecological and evolutionary factors at spatial scales intermediate to the local versus regional scales of traditional assembly models (Emerson \& Gillespie 2008; Jetz \& Fine 2012). The hierarchical organization of regions (e.g., large, evolutionarily-independent areas such as continents or oceanic islands) into environmentally-distinctive "sub-regions" (e.g., biomes) may shape the evolutionary buildup of species pools, thereby influencing the structure of local communities (Qian \& Ricklefs 2000; Zobel et al. 2011; Jetz \& Fine 2012; Mittelbach \& Schemske 2015).

If competition is relatively weak, increased diversification within a region should increase local community richness by increasing species additions relative to losses (Hubbell 2001; Leibold et al. 2004). Alternatively, if increased diversification produces species that specialize on particular sub-regions (e.g., Mayr 1947; Glor et al. 2003; Rundle \& Nosil 2005; Gray et al. 2019), it may spur the emergence of local richness controls. Subregional specialists may better monopolize local resources, resulting in competition-structured communities that can resist migrants (MacArthur 1972; Cornell \& Harrison 2014). Therefore, under this region/subregion/local model, a principal determinant of whether local or regional effects on diversity predominate is the availability of evolutionary opportunity - a term we use to describe the conditions necessary for clades to diversify and specialize on unique local ecological conditions (e.g., sufficient time and geographic space for speciation among or within ecologically distinct sub-regions to complete; Losos \& Parent 2010; Zobel et al. 2011; Cornell 2013; Algar \& Mahler 2015).

If greater evolutionary opportunities indeed facilitate local control, we predict the emergence of several ecological patterns in local-community abundance, species diversity, and organization across space (betadiversity). First, for communities to exhibit local diversity controls requires that they be saturated at the level of individuals competing for limited resources (Cornell 1999; Gaston 2000). Thus, numbers of individuals in such communities should scale with resource availability, yielding correlations between local abundance and proxies of productivity, such as temperature or elevation (Wright 1983; Gaston 2000). If individuals can utilize local resources efficiently regardless of the diversity of the evolutionary fauna, the scaling of abundance and productivity should be similar across systems that differ in evolutionary diversity. Conversely, greater diversification could fundamentally change how ecological limits manifest by generating specialists on previously unutilized resources and thereby enhancing community-level abundances (Cornell 2013; Storch et al. 2018; Storch \& Okie 2019). In that case, regions with greater evolutionary opportunity may exhibit greater local abundances in otherwise-similar environments.

Second, if greater macroevolutionary inputs enhance local control on species diversity then the relationship between environmental resources and local species richness should in theory be similar across regions. However, this relationship will depend on whether clades in different regions have had sufficient opportunity to diversify into the niches available in local environments - in other words, whether they have produced subregional environmental specialists that can saturate communities at the species level (Jetz \& Fine 2012; Cornell 2013). If a given region has had insufficient time or space for diversification to fill available sub-regional niches, we would expect local richness patterns across regions to diverge (MacArthur 1972; Mittelbach \& Schemske 2015).

Finally, if evolutionary opportunity shapes communities by facilitating local control, we expect greater regional diversity to sort primarily among communities (i.e., as beta-diversity) rather than within them (elevated alpha-diversity) (MacArthur 1965; Cornell 2013). Evolutionary opportunity should thus precipitate the emergence of spatial structure within faunas through the evolution of sub-regional environmental specialists. When opportunity is substantial in environmentally similar areas, whole-community properties such as total richness and functional characteristics may converge, even among evolutionarily-independent regions (Orians \& Paine 1983; Cornell 1999; Ricklefs 2006). By contrast, faunas lacking in evolutionary opportunity should consist of environmental generalists, and the local communities within these faunas should exhibit comparatively little turnover and potentially low convergence between faunas.

Testing how diversification affects local community structure is difficult, in part because of the challenge locating empirical systems that are ecologically similar, but differ in histories of macroevolutionary diver- 
sification (Lessard et al. 2012). Regions differing in evolutionary richness often also differ in climate and habitat, or the deep phylogenetic history of the biota, either of which may confound straightforward comparison (Rosenzweig 1995; Price et al. 2000). Ideally one would seek a system in which replicate regions are similar in environment, and contain faunas that radiated from recent phylogenetic stock, but differ in macroevolutionary diversity.

Here we leverage a natural experiment to examine the effects of macroevolution on the structure of local communities: independent radiations of anole lizards (Anolis ) distributed across similar environmental gradients on the Caribbean island of Jamaica and the northern paleoisland of adjacent Hispaniola (this region corresponds to a biogeographically distinctive unit within the island; Fig. 1). Anoles have diversified to play similar ecological roles on both islands, but Hispaniola has a richer anole fauna than its smaller neighbor Jamaica (Williams 1983; Losos 2009; Mahler et al. 2013). The two islands possess similar climates, vegetation types, and macrohabitat diversity (Ricklefs \& Bermingham 2008; Losos 2009). Notably, both feature vast expanses of hot lowland tropical forest that grade into tall inland mountains featuring cool cloudforest habitats. Their key environmental difference is that Hispaniola's highlands are much more extensive than Jamaica's, creating divergent evolutionary prospects in this sub-region type (Fig. 1b). Crucially, while the lowlands of both islands cover more than $3,000 \mathrm{~km}^{2}$, the proposed minimum area required for in situ speciation in anoles (Losos \& Schluter 2000), only Hispaniola's highlands clear this threshold, leading to the expectation that Jamaica's highland communities should be evolutionarily constrained.

We conducted mark-resample surveys of Anolis communities across matched elevational gradients on Jamaica and Hispaniola to test whether greater macroevolutionary diversity, and especially differences in highland evolutionary opportunity, trickle down to structure local communities. We begin by asking (1) whether the abundance of Anolis within local communities across elevations is similar between islands, as predicted if local temperature is primarily responsible for controlling community size, and macroevolutionary inputs have little effect on abundance. Next, we ask (2) whether differences in sub-regional area trigger divergence in community structure across elevations, such that community convergence exists between islands in the lowlands (where evolutionary opportunity is substantial), but is lacking in the highlands (for which Jamaica is more limited). We then investigate (3) whether greater evolutionary opportunity in the Hispaniolan highlands leads to ecologically distinct sub-faunas via the evolution of local environmental specialists. If so, we predict that Hispaniolan anole communities will exhibit greater beta-diversity than their Jamaican counterparts. Finally, we (4) test the importance of sub-regional faunas in impacting convergence in abundance and richness between islands across the elevational gradient.

\section{Methods}

\section{Sampling design}

We surveyed Anolis lizard communities in plots across the Dominican Republic (Hispaniola) and Jamaica between June and August of 2016-2018. We surveyed plots in 20 landscapes (13 on Hispaniola, 7 on Jamaica), distributed over broad temperature and precipitation gradients. Study landscapes were distributed from sea level to $2,380 \mathrm{~m}$ on the Dominican Republic (highest point is $3,098 \mathrm{~m}$ ) and to $1,923 \mathrm{~m}$ on Jamaica (highest point is $2,256 \mathrm{~m}$ ), and encompass an elevation range representing $>99.5 \%$ of the total land area of each island. Climate conditions were broadly similar in our sample (Fig. S1).

Each landscape contained 2-4 30m-diameter plots in forest habitat - the native climax vegetation $\left(\mathrm{N}_{\mathrm{DR}}=\right.$ $35, \mathrm{~N}_{\text {Jamaica }}=20$ ). An observer surveyed each plot six times. Each time, we marked any observed lizards with non-toxic paint following Heckel and Roughgarden (1979). Paint marks allowed us to identify re-sighted individuals, permitting estimation of total abundance for each species.

\section{Mark-resight model}

We used mark-resight models to estimate each species' abundance within each plot, while accounting for variation in detection probability across species, time of day, and observer. The model shared information about detection and abundance across sites and species, while allowing for site and species-specific deviations 
via random intercepts and slopes (Frishkoff et al. 2019). Doing so permits robust abundance and detection estimates of both common and rare species. Species abundance was predicted based on plot canopy openness, measured using a spherical densiometer, and mean annual temperature and precipitation variables. The latter were extracted from the Chelsa dataset (Kargeret al. 2017) using plot latitude and longitude.

Mark-resight models were implemented in a Bayesian framework using JAGS V4.2.0 (Plummer 2003) within the R V3.4.4 environment (Su \& Yajima 2014). For every species at every plot the model provided estimates of total abundance, and the effects of parameters related to environmental variables. A full model description is available in the supplement.

\section{Hypothesis testing}

To test whether community size scales identically with elevation on the two islands, as predicted if communities are locally saturated, we first regressed local community size (total number of individuals derived from mark-resight models) against elevation. Similarly, to assess whether greater regional diversity enhanced community-level species diversity across the same environmental gradient, we regressed resight-model-derived plot-level species richness against elevation. In both cases we used posterior means from the resight model to represent the best-estimate of true values.

We evaluated trajectories of abundance and species richness along elevation using linear mixed-effects models (LMMs). Our full model predicted the response as a function of linear and quadratic elevation terms, with full interactions with island identity. Models included a random intercept of landscape to acknowledge that multiple plots occurred in the same geographic area. We iteratively dropped terms from these models, comparing the full model with the nested model, until a likelihood-ratio test (evaluated against a chisquare distribution) indicated that all remaining terms were significant (alpha $=0.05$ ). We square-root transformed resight-model-derived abundance and species richness estimates to meet model assumptions of residual normality and homoscedasticity (log transformation-more typical of richness and abundance data - failed residual normality and homoscedasticity tests).

Next, to test whether greater macroevolutionary diversity facilitates the evolution of environmental specialists, thereby permitting greater partitioning of communities across space, we calculated abundance-weighted pairwise Bray dissimilarities between sites within each island using the betapart package (Baselga \& Orme 2012). We further examined abundance-weighted phylogenetic and morphological dissimilarity to assess whether differences in turnover had deeper evolutionary underpinnings, or resulted in ecomorphologically different community structures, respectively. To do so we used the time-calibrated phylogeny and measurements of ecologically-relevant morphological traits for Greater Antillean anoles presented in Mahler et al. (2013). We calculated phylogenetic dissimilarity of plots using abundance-weighted unifrac from the weighted_unifrac function within the abdiv package (Bittinger 2020). For morphological dissimilarity we calculated abundance-weighted mean pairwise distances between the species of all community pairs on each island in a morphospace of ecologically-relevant traits (the four-dimensional PC-space of Mahler et al. (2013), which represents $93 \%$ of total morphological variation across Greater Antillean Anolis lizards). In all cases we assessed the rate at which pairwise community dissimilarities changed as a function of pairwise elevation differences between sites on the same island. We used linear regression models including both linear and quadratic effects of elevation as well as an effect of island identity, and an island-by-elevation interaction.

Given that sub-regional faunas formed to differing degrees on the two islands, we evaluated whether similar environments led to whole-fauna morphological convergence at both island and sub-region levels, gauged using community mean morphology. We applied a cut-off of $700 \mathrm{~m}$ to split lowland and highland elevational zones into subregions. This elevation corresponded to the location of maximum turnover between highland and lowland species (but results are not sensitive to exact cutoff value). We assessed the abundance-weighted mean morphology along the four ecomorphological PC axes described above. To test whether morphology between faunas (or subfaunas) was more similar than expected by chance, we shuffled species morphologies 10,000 times, and examined where the observed Euclidean distance between fauna-mean morphologies fell relative to the permuted null distribution (we obtained two-tailed p-values by multiplying one-tailed p-values 
by two).

Finally, given the distinctiveness of the high-elevation fauna, we examined whether these species drove patterns of diversity within local communities across the elevational gradient. To do so we eliminated from the community dataset all highland species (species whose abundances are maximized above $700 \mathrm{~m}$, none of which occur at sea level). We then reassessed how both abundance and species richness of lowland species changed across the elevational gradient of each island using the same LMMs and model selection process described above.

\section{Results}

\section{Local abundance and richness across islands}

We first assessed whether total community size depended on macroevolutionary diversity or was instead set by local environmental conditions. Abundances within local communities varied substantially, but community size declined monotonically on both islands as elevation increased (Fig. 2a; best model: Elevation only, Elevation term: $\mathrm{P}<0.001$; marginal $\left.\mathrm{R}^{2}=0.57\right)$. Despite the nearly 2 -fold difference in gamma diversity between faunas (11 in northern Hispaniola versus 6 in Jamaica), local communities at a given elevation possessed a statistically indistinguishable number of Anolis individuals (Island term: $\mathrm{P}=0.70$ ), and local abundance declined with elevation at similar rates $\left(\right.$ Island $^{*}$ Elevation interaction $\mathrm{P}=0.11$ ).

But while abundance patterns are similar across islands, the way that diversity is partitioned over the elevational gradient is not equivalent (Island ${ }^{*}$ Elevation interaction $\mathrm{P}<0.001$, Elevation ${ }^{2}$ term $\mathrm{P}<0.001$, marginal $R^{2}=0.86$ ). As predicted by the evolutionary opportunity model, Jamaica and Hispaniola have equivalent species richness in lowland communities, where opportunity is substantial. But above the lowlands the trajectory diverges: Jamaica displays a steady loss of species with elevation, while Hispaniola contains a mid-elevation hump, followed by a slow decline. Notably, above the lowlands $(>500 \mathrm{~m})$ communities are consistently richer on Hispaniola than Jamaica (Fig. 2b).

\section{Community partitioning into sub-faunas}

As predicted by the availability of greater highland evolutionary opportunity in Hispaniola, the two faunas diverge in community turnover across elevations. As such, total beta-diversity is greater on Hispaniola than Jamaica, and Hispaniola's beta-diversity derives almost entirely from among-site species turnover (Table 1). Jamaica, in contrast, shows markedly less turnover, with a substantial portion of its compositional dissimilarity stemming from gradients in richness and abundance. This difference is a community-level signature from the evolution of high-elevation specialists on Hispaniola. Specifically, the Hispaniolan fauna contains 5 species that are broadly distributed across the lowlands, 1 that is a specialist on dry lowland regions, and 5 that maximize their abundance above $700 \mathrm{~m}$ and do not occur at sea level. By comparison, Jamaica has 5 species that are distributed across the lowlands, and only 1 high-elevation specialist.

Hispaniola's species are partitioned into two entirely distinct sub-faunas: the lowest and highest communities share no species in common. In contrast, some of the lowland species in Jamaica are among those that persist at the highest sites (Fig 3a-c). Interestingly the elevated beta-diversity of Hispaniola contains a strong phylogenetic signal linked to historical elevational specialization. The Hispaniolan highland fauna appears to be derived from a combination of in situ radiation and evolutionary colonization from lowland derived species. While two highland species each have a lowland species as their closest relative, the most abundant highland forest understory species primarily derive from a single clade, which colonized the highlands reasonably early in the history of the island, seeming to have initiated an adaptive radiation in miniature (Fig $3 \mathrm{~d}, \mathrm{e}$ ). The presence of this clade drives the formation of the sub-regional fauna on Hispaniola, resulting in substantial elevational turnover that is absent from Jamaica.

Evolution of this highland sub-fauna on Hispaniola also results in community-level differences in functional trait distribution. Average morphology on Hispaniola diverges between lowland and highland communities but remains steady on Jamaica across elevations (Fig 3f). Different environments in the highlands and 
lowlands should require different morphological solutions for optimal fitness. Given ample evolutionary opportunity, communities in similar environments should reach the same solution. Indeed, the community abundance-weighted mean morphology in the lowlands of Jamaica and Hispaniola is extremely similar (Fig. $3 \mathrm{~g}$ ) - more similar than expected if species morphologies are randomly shuffled (Fig. 4, $\mathrm{P}=0.033$ ). In contrast the highlands are morphologically distinct, without evidence for convergence between islands $(\mathrm{P}=0.44)$, suggesting that evolutionary opportunity on Hispaniola has created a community unique in both diversity and morphology, that has not been reproduced on Jamaica. As a result, islandwide average morphologies are not more similar across islands than expected by chance (Fig. S2, $\mathrm{P}=0.076$ )

Finally, the development of the high-elevation fauna on Hispaniola appears to have granted access to niche space that would otherwise go unoccupied by elevational generalists. For example, on Hispaniola above 1800m three species were common and species continued to occupy montane forests up until 2,300m (Fig 2b,c). But while Jamaica reaches $2,250 \mathrm{~m}$ at its peak, we detected no anoles in the forests at or above $1800 \mathrm{~m}$ (however, even with no detections at the 4 highest plots over six two-hour surveys, resight models cannot rule out a small number of individuals, and so model-predicted species richnesses are non-zero; as in Fig. 1b).

Community structure along environmental gradients

Given differences in regional sub-faunas on the two islands we sought to understand the consequences of these sub-faunas for local diversity. To do so, we again examined alpha-diversity patterns on each island by elevation, but eliminated from analysis the five species on Hispaniola and single species on Jamaica that do not occur at sea level. With these highland species absent, abundance trajectories are no longer statistically indistinguishable between islands: total community size declines much more rapidly on Hispaniola than Jamaica $\left(\right.$ Island $^{*}$ Elevation interaction, $\mathrm{P}=0.021 ;$ Island $^{*}$ Elevation ${ }^{2}$ interaction $\mathrm{P}=0.025, \mathrm{R}^{2}=0.80$; Comparison to model with no island effects, $\mathrm{P}=0.009)$. Specifically Hispaniola shows a lizard deficit at middle and high elevations with respect to Jamaica, while the presence of some Jamaican lowland species that still occur in middle elevations means that eliminating highland species had relatively little effect on Jamaica's lizard abundances (Fig. 4a).

In contrast, when high-elevation specialists are eliminated species richness patterns along the elevational gradient become equivalent, with the best-fit model including only a linear elevation term (Elevation term $\mathrm{P}<0.001$, marginal $\mathrm{R} 2=0.88$ ). Without the highland species Hispaniola loses its middle-elevation hump in local species richness, and lowland species disappear from communities at roughly the same rate with increasing elevation on both islands (Fig. 4b, All island effects non-significant:Island ${ }^{*}$ Elevation $^{2}$ interaction $\mathrm{P}=0.51$, Island $^{*}$ Elevation interaction $\mathrm{P}=0.43$, Island effect $\left.\mathrm{P}=0.13\right)$.

\section{Discussion}

\section{Diversification strengthens local controls on community structure}

Our results reveal a complex signature of macroevolutionary processes on local community structure, supporting a model in which diversification both strengthens local controls on community diversity within biomes, and elevates local diversity at biome transition zones where sub-faunas abut and mix. Critically, our data suggest that factors promoting the evolution of sub-regional ecological specialists (e.g. Zobel et al. 2011; Jetz \& Fine 2012) may be key to determining whether communities achieve local diversity controls at the species level.

Surveying lizard communities on neighboring islands that differ in evolutionary richness but otherwise contain similar environments, we uncovered several patterns predicted if macroevolutionary inputs facilitate the emergence of local diversity controls. First, total community abundances strongly suggest local controls, declining similarly with elevation on Jamaica and Hispaniola, despite a two-fold difference in evolutionary diversity between faunas. Total community sizes on both islands thus appear limited by individual-level competition - most likely for dietary resources (i.e., energy). Interestingly, these patterns revealed little support for macroevolution raising local carrying capacities (e.g., by producing more efficient specialists; Cornell 2013; Storch \& Okie 2019), although the slightly greater abundance of Hispaniolan anoles at the 
highest elevations may represent weak evidence for such an effect.

Second, we found that local patterns of species diversity were similar between Jamaica and Hispaniola where both islands provide ample opportunities for the evolution of endemic habitat specialists (the lowlands), but diverged in areas where opportunities differ starkly (the highlands). In the lowlands, average species diversity and average community morphology were nearly identical between islands despite the larger area and greater regional diversity of Hispaniola. Such similarity suggests that local limits on species diversity have been reached in the lowland tropical forest habitats that predominate both islands (Cornell 1999; Ricklefs 2006). However, community structure diverged in the highlands, with local species richness on Hispaniola exceeding that on Jamaica at elevations greater than $\sim 700 \mathrm{~m}$ (Fig. 2b). Hispaniolan highland communities were also phenotypically distinctive, occupying a region of morphospace that differs from all sub-regions on either island. In contrast, the average morphology of Jamaica's highland communities is indistinguishable from the lowlands, in part reflecting the fact that the highlands are largely composed of elevational generalist species (Fig. 3c,g; Table 1). This pronounced highland diversity difference suggests that Jamaica's high-elevation anole communities are undersaturated at the species level (Cornell 1999; Mateo et al. 2017), despite having similar abundances to those on Hispaniola.

Finally, as predicted if macroevolutionary inputs strengthen local controls (Cornell 2013), the greater evolutionary diversity of anole species on Hispaniola was associated with greater compositional turnover among local communities (Table 1). This pattern was linked to the evolution of distinctive elevational sub-faunas on Hispaniola, but not Jamaica (Fig. 3).

\section{Evolutionary opportunity and the assembly of faunas and communities}

Community abundance patterns suggest at least broadly comparable resources for anoles in tropical montane forests on Hispaniola and Jamaica. So why are Jamaica's montane communities less diverse? Ecological explanations such as colonization limitation are unlikely - all Jamaican anole species not found in highland communities are otherwise distributed islandwide, and no obvious barriers prevent colonization. Instead, diversity differences are best explained by the relative paucity of high-elevation specialists in the species pool of Jamaica - indeed, computationally "deleting" the endemic highland subfaunas of each island reconciles their divergent relationships between local species richness and elevation (Fig. 4). Thus, to understand Jamaica and Hispaniola's highland community differences, we must turn to the evolutionary buildup of their species pools (Jetz \& Fine 2012; Cornell 2013; Mittelbach \& Schemske 2015).

Speciation-driven contributions to highland diversity could arise either by evolutionary colonization, in which lowland-derived lineages evolve to tolerate or specialize on cool upland conditions, or by in situ radiation from a highland ancestor (Ricklefs 2006; Rosindell \& Phillimore 2011). The first mechanism has occurred on both islands, but appears difficult, with only one instance on Jamaica and a just a handful in northern Hispaniola. Indeed, evolutionary transitions of this sort appear to be rare, with one study estimating that speciation across biomes is $\sim 25$ times less likely than within them (Crispet al. 2009). The second mechanism, in situ highland radiation, occurred exclusively on Hispaniola, where a clade of highland-endemic anoles diversified into a variety of ecological types (Figure 3e), raising the taxonomic, functional, and phylogenetic uniqueness of the Hispaniolan highlands. The smaller cumulative area of Jamaica's highlands likely precluded enrichment of its montane fauna via this mechanism. Allopatric separation of populations is likely a prerequisite for speciation in anoles (Glor et al. 2004, 2005), and anoles likely need at least $3000 \mathrm{~km}^{2}$ to undergoin situ speciation (Losos \& Schluter 2000). The highland "sky island" in northern Hispaniola above 700m clears this threshold with $4000 \mathrm{~km}^{2}$ (Fig. 1), yet Jamaica's equivalent zone occupies less than $400 \mathrm{~km}^{2}$. Thus the rarity of cross-biome speciation events, plus insufficient space for subsequentin situ radiation, appear to have deprived highland Jamaica from the 2-3 additional species supported locally at similar elevations on Hispaniola.

In contrast to the highlands, the lowlands on both islands are large, well over the $3000 \mathrm{~km}^{2}$ threshold. Even though the lowlands of northern Hispaniola are nearly $5 \mathrm{X}$ larger than in Jamaica $\left(18,500\right.$ versus $\left.3,900 \mathrm{~km}^{2}\right)$, alpha-diversity in the lowlands is identical, suggesting that local diversity caps predominate, and have been 
reached. Northern Hispaniola's greater total diversity thus appears to come about not because it is larger per se, but because its high-elevation biome is large enough to generate an additional set of distinct species, boosting diversity from 6 species (lowland only) to 11 (total).

A growing body of recent work has revealed the importance of geographical and environmental determinants of evolutionary radiation in setting regional diversity patterns (Fine \& Ree 2006; Jetz \& Fine 2012; Quintero \& Jetz 2018). Our work shows that such "evolutionary opportunities" can also structure communities by producing species capable of maintaining local diversity equilibria. Such equilibria are consistent with evidence from temporal studies of local-scale diversity, which provide evidence for stable community-level richness limits over timescales ranging from decades to tens of millions of years (Bambach 1977; Brown et al. 2001; Gotelli et al. 2017; Closeet al. 2019). However, they contrast with local diversity patterns in Hawaiian trees, one of very few other groups to be investigated for signatures of macroevolution on local community structure (Craven et al. 2019). In that system, greater island-level evolutionary diversity was linked to increased local-scale diversity, suggesting that local diversity caps in that system either have not yet been reached, or are more easily overridden. Understanding this difference will require further research, and we suggest that the likelihood that evolution will strengthen local controls will depend on potentially system-specific mechanisms of dispersal, competition, and coexistence. For example, compared to tropical trees, anoles are poorer dispersers (Williams 1969), more likely to engage in interference competition (Schoener 1977; Culbertson \& Herrmann 2019), and, lacking dormancy, less likely to benefit from temporal storage effects (Chesson \& Warner 1981), all of which could favor the primacy of local controls in anole communities.

\section{Regional contributions to diversity at biological suture zones}

Even if communities are effectively saturated with individual organisms, species richness may still be augmented by regional diversity where processes that remove species with redundant niches (e.g. competitive exclusion) are slow relative to those that add them (e.g. immigration from nearby areas) (Cornell \& Harrison 2014). We see no evidence for such regional signatures in the lowlands on either island, or above $>1200 \mathrm{~m}$ on Hispaniola. However, the evolution of distinct elevational sub-faunas on Hispaniola is accompanied by a mid-elevation diversity peak where low-elevation and high-elevation faunas meet, consistent with an ecotoneassociated dynamic equilibrium (Storch \& Okie 2019). Middle elevations may be especially susceptible to mixing if fitness differences equilibrate between lowland and highland-adapted species with redundant dietary or structural niches, preventing clear competitive dominance (Chesson 2000). Although hypothesized to be common (Lomolino 2001), such mid-elevation richness peaks appear infrequently in reptiles (McCain 2010), and maximum diversity only rarely occurs at transition zones between reptile faunas (McCain \& Beck 2016).

Our results suggest two potential reasons. First, faunal mixing can only occur where evolutionary opportunities allow faunas at either end of an environmental gradient to have sufficient species to result in richness increases where faunas meet. On Jamaica, a highland sub-fauna of one is insufficient to engender a middleelevation diversity peak, given that several lowland species have already been lost. Our data thus point to a key role for evolutionary opportunity in determining whether an elevational gradient is likely to exhibit a middle-elevation peak in alpha-diversity (e.g., Hispaniola) or not (Jamaica). Indeed, deletion of highland endemics, which are much more diverse on opportunity-rich Hispaniola, obliterates the middle-elevation diversity peak on that island, and creates a middle-elevation abundance deficit, just as expected if highland and lowland species co-occurring at the ecotone are competing for limited resources in communities saturated at the individual level (MacArthur et al. 1972).

Second, the emergence of local diversity peaks at sub-region boundaries will depend on the dispersal abilities of community members. Anoles are relatively poor dispersers (Williams 1969), so mass and rescue effects that facilitate persistence in unfavorable conditions should be minimal. As such, the mid-elevation diversity peak on Hispaniola is fairly narrow. Ecotone peaks would be wider for stronger dispersers, and in the extreme case could encompass an entire environmental gradient, supplementing alpha-diversity island-wide.

\section{Conclusion}


Taken together, our results emphasize the role of macroevolutionary diversity in determining community structure. Over ecological time, communities at different compositional start points will converge to similar functional members, even if species identity varies (Fukamiet al. 2005). We suggest a similar process of community filling over evolutionary time - so long as evolutionary opportunity is available, speciation can fill local communities, allowing them to follow similar ecological trajectories. Evolutionary opportunity allows for regional environmental specialists to form, increasing beta-diversity and supplementing alpha-diversity at biological suture zones. Where speciation is comparatively limited, widespread species fill rare environments as best they are able, but sub-regional faunas are unable to form, and local diversity in the rare environments and their suture zones remains impoverished. Accounting for such dynamics may help reconcile contradictory results in elevation diversity profiles across systems, and shed new light on how local or regional factors control community structure and diversity.

\section{Acknowledgements}

We thank C. Boccia, S. Senthivasan, I. Borges, M. Balanaser, B. Downer-Bartholomew, G. Sandler, E. Folfas, S. Gopalan, P. Otwey, H. McIlwraith, S. Leslie, E. Gabot, C. Marte, M. Landestoy, M. J. Rodríguez Bobadilla, N. Cruz, I. J. Wang, G. O. U. Wogan, P. L. Skipwith, L. Maier, J. Pauel, B. Wilson, D. Robinson, P. Parra, Mr. French, Newton, Tall Man, Mauleen, R. Love, J. Schroeter, R. Poyser, W. Taylor, S. Otuokon, and the Jamaica Conservation and Development Trust for help during fieldwork. Research permission was granted by the Ministerio de Medio Ambiente y Recursos Naturales, Dominican Republic (0000818), and National Environment and Planning Agency, Jamaica (\#18/27). Access to private land was graciously provided by M. Mejía, the Punta Cana Ecological Reserve, I. Conolley, D. Twyman, D. Bernard, the Petroleum Corp. of Jamaica, C. Read, and the PWD Gun Club. A NSERC Discovery Grant (RGPIN-2015-04334) and the U. of Toronto FAS Research Excursion Program provided research funding. This research complies with CCAC ethics guidelines and was approved by the University of Toronto Local Animal Care Committee (AUC Protocol 20011469).

\section{References}

Algar, A.C. \& Mahler, D.L. (2015). Area, climate heterogeneity, and the response of climate niches to ecological opportunity in island radiations of Anolis lizards. Glob. Ecol. Biogeogr. , 25, 781-791.

Bambach, R.K. (1977). Species Richness in Marine Benthic habitats through the Phanerozoic. Paleobiology , 3, 152-167.

Baselga, A. \& Orme, C.D.L. (2012). Betapart: An R package for the study of beta diversity. Methods Ecol. Evol. , 3, 808-812.

Baselga, A., Orme, D., Villeger, S., Bortoli, J. De \& Leprieur, F. (2018). betapart: Partitioning Beta Diversity into Turnover and Nestedness Components.

Bittinger, K. (2020). abdiv: Alpha and Beta Diversity Measures.

Brown, J.H., Morgan Ernest, S.K., Parody, J.M. \& Haskell, J.P. (2001). Regulation of diversity: Maintenance of species richness in changing environments. Oecologia , 126, 321-332.

Chesson, P. (2000). Mechanisms of maintenance of species diversity.Annu. Rev. Ecol. Syst., 31, 343-366.

Chesson, P.L. \& Warner, R.R. (1981). Environmental Variability Promotes Coexistence in Lottery Competitive Systems. Am. Nat., 117, 923-943.

Close, R.A., Benson, R.B.J., Alroy, J., Behrensmeyer, A.K., Benito, J., Carrano, M.T., et al. (2019). Diversity dynamics of Phanerozoic terrestrial tetrapods at the local-community scale. Nat. Ecol. Evol. , 3, 590-597.

Cornell, H. V. (1999). Unsaturation and regional influences on species richness in ecological communities: A review of the evidence.Ecoscience, 6, 303-315. 
Cornell, H. V. (2013). Is regional species diversity bounded or unbounded? Biol. Rev. , 88, 140-165.

Cornell, H. V. \& Harrison, S.P. (2014). What are species pools and when are they important? Annu. Rev. Ecol. Evol. Syst. , 45, 45-67.

Craven, D., Knight, T.M., Barton, K.E., Bialic-Murphy, L. \& Chase, J.M. (2019). Dissecting macroecological and macroevolutionary patterns of forest biodiversity across the Hawaiian archipelago. Proc. Natl. Acad. Sci. U. S. A. , 116, 16436-16441.

Crisp, M.D., Arroyo, M.T.K., Cook, L.G., Gandolfo, M.A., Jordan, G.J., McGlone, M.S., et al. (2009). Phylogenetic biome conservatism on a global scale. Nature , 458, 754-756.

Culbertson, K.A. \& Herrmann, N.C. (2019). Asymmetric interference competition and niche partitioning between native and invasive Anolis lizards. Oecologia , 190, 811-820.

Emerson, B.C. \& Gillespie, R.G. (2008). Phylogenetic analysis of community assembly and structure over space and time. Trends Ecol. Evol., 23, 619-30.

Fine, P.V.A. \& Ree, R.H. (2006). Evidence for a time-integrated species-area effect on the latitudinal gradient in tree diversity. Am. Nat. , 168, 796-804.

Frishkoff, L.O., Gabot, E., Sandler, G., Marte, C. \& Mahler, D.L. (2019). Elevation shapes the reassembly of Anthropocene lizard communities. Nat. Ecol. Evol. , 3, 638-646.

Fukami, T., Bezemer, T.M., Mortimer, S.R. \& Van Der Putten, W.H. (2005). Species divergence and trait convergence in experimental plant community assembly. Ecol. Lett. , 8, 1283-1290.

Gaston, K.J. (2000). Global patterns in biodiversity. Nature , 405, 220-227.

Glor, R.E., Gifford, M.E., Larson, A., Losos, J.B., Lara, A.R.C., Jackman, T.R., et al. (2004). Partial island submergence and speciation in an adaptive radiation: a multilocus analysis of the Cuban green anoles. Proc. Biol. Sci. , 271, 2257-2265.

Glor, R.E., Kolbe, J.J., Powell, R., Larson, A. \& Losos, J. (2003). Phylogenetic analysis of ecological and morphological diversification in Hispaniolan trunk-ground anoles (Anolis cybotes group).Evolution , 57, 2383-2397.

Glor, R.E., Losos, J.B. \& Larson, A. (2005). Out of Cuba: Overwater dispersal and speciation among lizards in the Anolis carolinensis subgroup. Mol. Ecol. , 14, 2419-2432.

Gotelli, N.J., Shimadzu, H., Dornelas, M., McGill, B., Moyes, F. \& Magurran, A.E. (2017). Community-level regulation of temporal trends in biodiversity. Sci. Adv., 3.

Gray, L.N., Barley, A.J., Poe, S., Thomson, R.C., Nieto-Montes de Oca, A. \& Wang, I.J. (2019). Phylogeography of a widespread lizard complex reflects patterns of both geographic and ecological isolation. Mol. Ecol. , 28, 644-657.

Harrison, S. \& Cornell, H. (2008). Toward a better understanding of the regional causes of local community richness. Ecol. Lett. , 11, 969-979.

Hubbell, S.P. (2001). The Unified Neutral Theory of Biodiversity and Biogeography. Princeton University Press, Princeton, NY.

Jetz, W. \& Fine, P.V.A. (2012). Global gradients in vertebrate diversity predicted by historical areaproductivity dynamics and contemporary environment. PLoS Biol., 10.

Karger, D.N., Conrad, O., Böhner, J., Kawohl, T., Kreft, H., Soria-Auza, R.W., et al. (2017). Climatologies at high resolution for the earth's land surface areas. Sci. Data , 4, 170122.

Leibold, M.A. \& Chase, J.M. (2018). Metacommunity Ecology, Volume 59 . Princeton University Press. 
Leibold, M.A., Holyoak, M., Mouquet, N., Amarasekare, P., Chase, J.M., Hoopes, M.F., et al. (2004). The metacommunity concept: A framework for multi-scale community ecology. Ecol. Lett. , 7, 601-613.

Lessard, J.P., Borregaard, M.K., Fordyce, J.A., Rahbek, C., Weiser, M.D., Dunn, R.R., et al. (2012). Strong influence of regional species pools on continent-wide structuring of local communities.Proc. R. Soc. B Biol. Sci. , 279, 266-274.

Lomolino, M. V. (2001). Elevation gradients of species-density: historical and prospective views. Glob. Ecol. Biogeogr. , 10, 3-13.

Losos, J.B. (2009). Lizards in an Evolutionary Tree: Ecology and Adaptive Radiation of Anoles . First. University of California Press, Berkeley, CA.

Losos, J.B. \& Parent, C.E. (2010). The speciation-area relationship. In: The theory of island biogeography revisited . Princeton University Press, Princeton, pp. 415-438.

Losos, J.B. \& Schluter, D. (2000). Analysis of an evolutionary species-area relationship. Nature , 408, 847850 .

MacArthur, R.H. (1965). Patterns of Species Diversity. Biol. Rev. , 40, 510-533.

MacArthur, R.H. (1972). Geographical Ecology . Harper and Row, New York.

MacArthur, R.H., Diamond, J.M. \& Karr, J.R. (1972). Density Compensation in Island Faunas. Ecology , $53,330-342$.

MacArthur, R.H. \& Wilson, E.O. (1967). The Theory of Island Biogeography . Princeton University Press, Princeton, NJ.

Mahler, D.L., Ingram, T., Revell, L.J. \& Losos, J.B. (2013). Exceptional Convergence on the Macroevolutionary Landscape in Island Lizard Radiations. Science , 341, 292-295.

Mateo, R.G., Mokany, K. \& Guisan, A. (2017). Biodiversity Models: What If Unsaturation Is the Rule? Trends Ecol. Evol. , 32, 556-566.

Mayr, E. (1947). Ecological Factors in Speciation. Evolution , 1, 263-288.

McCain, C.M. (2010). Global analysis of reptile elevational diversity. Glob. Ecol. Biogeogr. , 19, 541-553.

McCain, C.M. \& Beck, J. (2016). Species turnover in vertebrate communities along elevational gradients is idiosyncratic and unrelated to species richness. Glob. Ecol. Biogeogr. , 25, 299-310.

McPeek, M.A. \& Brown, J.M. (2000). Building a regional species pool: Diversification of the Enallagma damselflies in eastern North America.Ecology , 81, 904-920.

Mittelbach, G.G. \& Schemske, D.W. (2015). Ecological and evolutionary perspectives on community assembly. Trends Ecol. Evol. , 30, 241-247.

Myers, J.A., Chase, J.M., Jiménez, I., Jørgensen, P.M., Araujo-Murakami, A., Paniagua-Zambrana, N., et al. (2013). Beta-diversity in temperate and tropical forests reflects dissimilar mechanisms of community assembly. Ecol. Lett. , 16, 151-157.

Orians, G.H. \& Paine, R.T. (1983). Convergent evolution at the community level. In: Coevolution (eds. Futuyma, D. \& Slatkin, M.). Sinauer Associates, pp. 431-458.

Plummer, M. (2003). JAGS: A program for analysis of Bayesian graphical models using Gibbs sampling. Proc. 3rd Int. Work. Distrib. Stat. Comput. , 20-30.

Price, T., Lovette, I.J., Bermingham, E., Gibbs, H.L. \& Richman, A.D. (2000). The imprint of history on communities of North American and Asian warblers. Am. Nat., 156, 354-367. 
Qian, H. \& Ricklefs, R.E. (2000). Large-scale processes and the Asian bias in species diversity of temperate plants. Nature, 407, 180-182.

Quintero, I. \& Jetz, W. (2018). Global elevational diversity and diversification of birds. Nature, 555, 246-250.

Rabosky, D.L. \& Hurlbert, A.H. (2015). Species richness at continental scales is dominated by ecological limits. Am. Nat. , 185, 572-583.

Ricklefs, R. \& Bermingham, E. (2008). The West Indies as a laboratory of biogeography and evolution. Philos. Trans. R. Soc. B Biol. Sci. , 363, 2393-2413.

Ricklefs, R.E. (1987). Community Diversity: Relative Roles of Local and Regional Processes. Science , 235, $167-171$.

Ricklefs, R.E. (2006). Evolutionary diversification and the origin of the diversity-environment relationship. Ecology , 87, 3-13.

Ricklefs, R.E. \& Schluter, D. (1994). Species diversity in ecological communities: historical and geographical perspectives . University of Chicago Press.

Rosenzweig, M.L. (1995). Species diversity in space and time . Cambridge Univ Pr.

Rosindell, J. \& Phillimore, A.B. (2011). A unified model of island biogeography sheds light on the zone of radiation. Ecol. Lett. , 14, 552-560.

Rundle, H.D. \& Nosil, P. (2005). Ecological speciation. Ecol. Lett. , 8, 336-352.

Schoener, T.W. (1977). Competition and the niche. Biol. Reptil. , 7, 35-136.

Storch, D., Bohdalková, E. \& Okie, J. (2018). The more-individuals hypothesis revisited: the role of community abundance in species richness regulation and the productivity-diversity relationship.Ecol. Lett. , 21, 920-937.

Storch, D. \& Okie, J.G. (2019). The carrying capacity for species richness. Glob. Ecol. Biogeogr. , 28, 15191532 .

Su, Y.-S. \& Yajima, M. (2014). R2jags: A Package for Running jags from R.

Swenson, N.G. (2011). Phylogenetic Beta Diversity Metrics, Trait Evolution and Inferring the Functional Beta Diversity of Communities.PLoS One, 6, e21264.

Vellend, M. (2016). The theory of ecological communities (MPB-57) . Princeton University Press.

Williams, E.E. (1969). The Ecology of Colonization as Seen in the Zoogeography of Anoline Lizards on Small Islands. Q. Rev. Biol. , 44, 345-389.

Williams, E.E. (1983). Ecomorphs, Faunas, Island Size, and Diverse End Points in Island Radiations of Anolis. In: Lizard Ecology .

Wright, D.H. (1983). Species-Energy Theory: An Extension of Species-Area Theory. Oikos , 41, 496-506.

Zobel, M., Otto, R., Laanisto, L., Naranjo-Cigala, A., Pärtel, M. \& Fernández-Palacios, J.M. (2011). The formation of species pools: Historical habitat abundance affects current local diversity. Glob. Ecol. Biogeogr. , 20, 251-259.

\section{Tables}

Table 1: Islandwide beta-diversity partitioning based on site presence-absence (Incidence) or Abundance. Total community dissimilarity is partitioned into a component deriving from species replacement between sites ("Turnover" and "Balancing"), versus from differences in richness or abundance between sites ("Nestedness" and "Gradient"). 


\begin{tabular}{llll}
\hline Type & Component & Hispaniola & Jamaica \\
\hline \multirow{3}{*}{ Incidence } & Turnover & 0.86 & 0.50 \\
& Nestedness & 0.03 & 0.17 \\
& Total & 0.90 & 0.67 \\
Abundance & Balancing & 0.86 & 0.59 \\
& Gradient & 0.07 & 0.22 \\
& Total & 0.93 & 0.81 \\
\hline
\end{tabular}

\section{Figures}
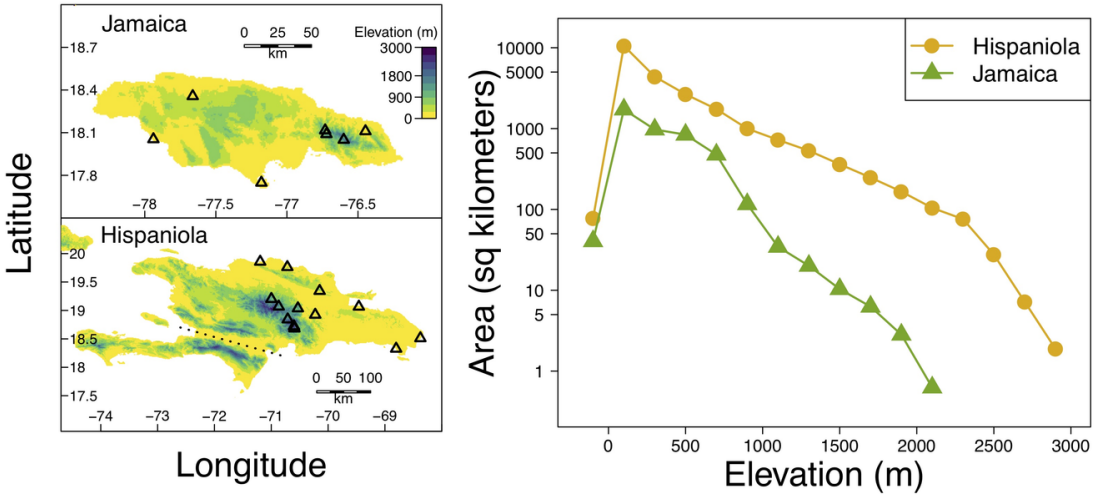

Figure 1: Left hand panels show maps of study site locations (triangles) along the elevational gradients on both islands. Dashed line on Hispaniola separates the North paleoisland, from the south paleoisland-locations that have had separate evolutionary histories during periods of higher sea levels, and which have different species pools. Note that maps of Jamaica and Hispaniola are not on same scale. Right hand panel illustrates the total area (y-axis on log scale) in $200 m$ elevational bands on both islands. Note the steep drop off in area on Jamaica above $700 m$.
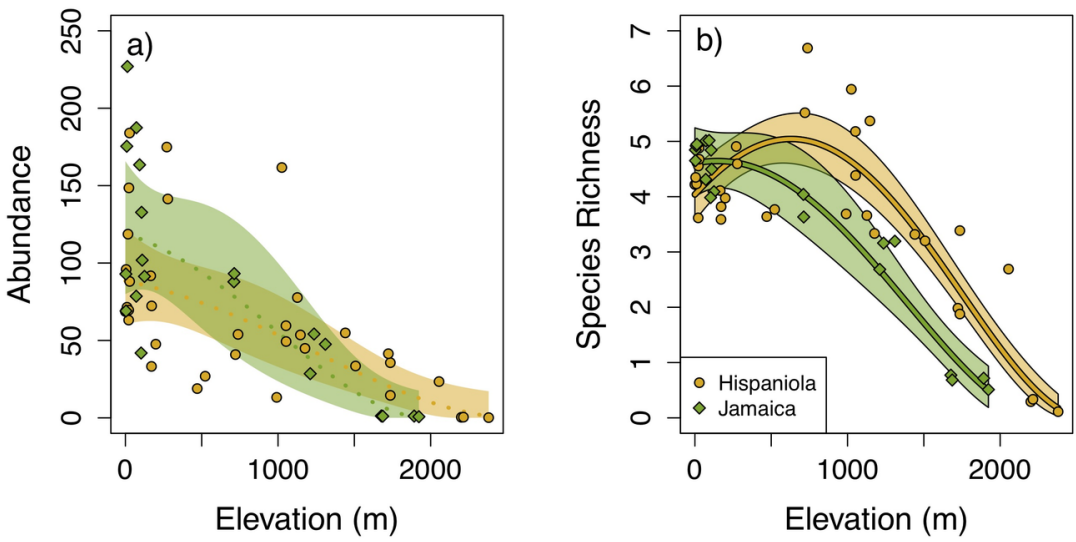

Figure 2: Anolis abundance and species richness across survey plots on both islands. (a) Total Anolis abundance declines monotonically with elevation and is statistically indistinguishable between islands. The depicted model includes linear and quadratic effects of elevation and full interactions with island identity, though only the effect of elevation is statistically significant after backwards model selection. (b) Species 
richness patterns along elevational gradients deviate between islands ranging from rough equivalency in the lowlands to greater species richness in the Hispaniolan fauna upslope. Figure depicts model best fit lines on Jamaica (green) and Hispaniola (yellow), with shaded regions representing standard error. Significant differences between islands are emphasized with black borders around best fit lines and standard error regions in panel $b$. Points represent posterior mean abundance and species richness at study plots derived from mark-resight models $\left(N_{\text {Jamaica }}=20, N_{\text {Hispaniola }}=35\right)$.

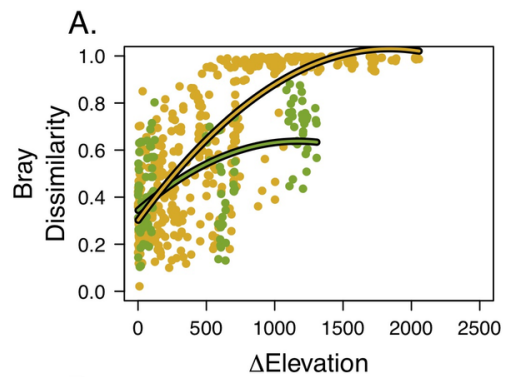

$$
\text { D. }
$$

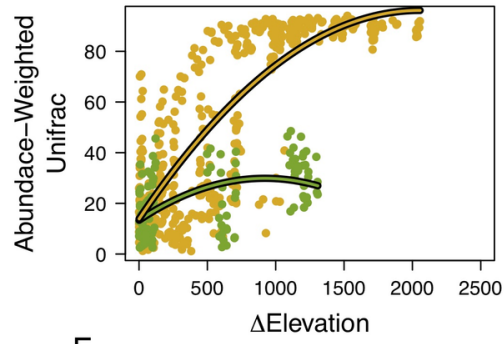

F.

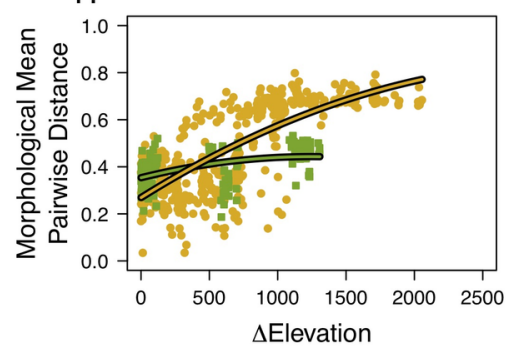

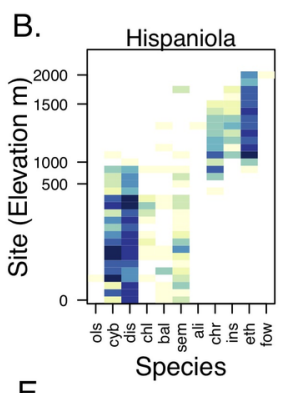

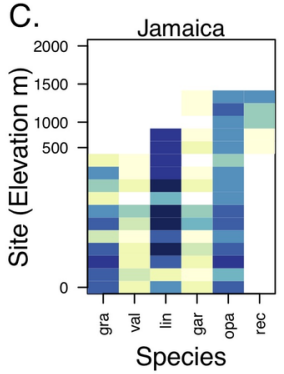

E.

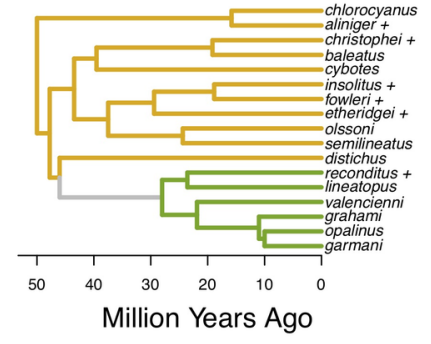

G.

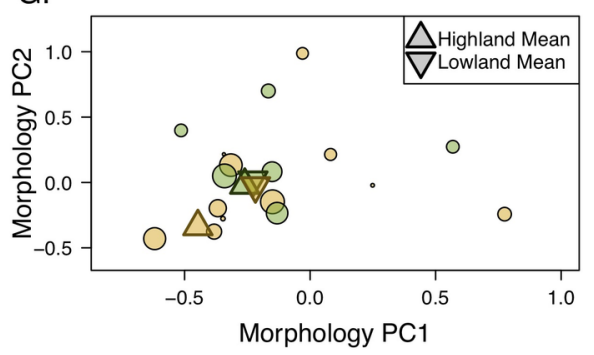

Figure 3. Greater macroevolutionary diversity on Hispaniola generates a high-elevation fauna. (a) Pairwise plot-level community dissimilarity based on species identity against the differences in elevation between plots. $(b$ and $c)$ Heat map showing abundance of species in all plots along the elevational gradient. Sites are organized along the $y$-axis so that lowest elevation sites are on the bottom and highest are on top. Tick marks along y-axis show $500 \mathrm{~m}$ increments. Note that y-axes are not scaled uniformly within islands, because low elevation habitats are more common and thus preferentially sampled, and are not identical across islands, as sampling sites were not matched by elevation. Species along the x-axis are organized by mean elevation at which the species occurs. Note (1) the distinct highland species on Hispaniola, and (2) differences between islands in elevation at which no anoles occur. (d) Pairwise phylogenetic dissimilarity of plots as in ' $b$ ' highlighting the phylogenetic turnover along elevation on Hispaniola. (e) Phylogeny of all Anolis species observed with branches colored according to island. ' + ' indicates highland species (species not observed at sea-level). (f) Pairwise morphological dissimilarity between plots as in ' $b$ ' highlighting greater morphological dissimilarity between elevation zones on Hispaniola. (g). Location in morphospace of all observed species along first two morphological principal component axes from 11 morphometric measurements. PC1 corresponds to limb-length whereas PC2 corresponds to overall body size. Circle size represents overall abundance 
of the species across all plots. Triangles depict the abundance weighted morphological means of all plots in the lowlands (<700m asl) and the highlands (>700m asl) on both islands. In all plots (except $b$ and c) yellow indicates plots or species in Hispaniola whereas green indicates those in Jamaica.
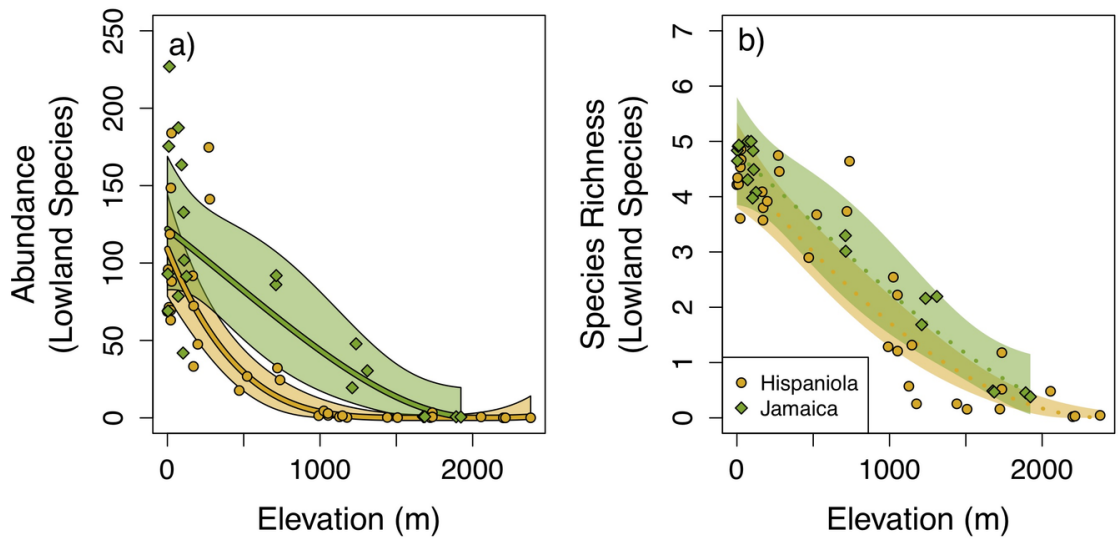

Figure 4: Lowland species abundance and richness across elevation. (a) Abundance of all lizard individuals in plots across elevations, evaluating only species that have maximum abundances $<700 m$. When discounting the highland fauna, Hispaniola has fewer individuals at middle elevations, though total abundance is still equivalent between islands near sea level. Compare to Fig. 2a, analyzing all species and showing equivalent abundance profiles by elevation across islands. (b) Species richness in plots, evaluating only lowland species. Removing the highland species yields extremely similar alpha-diversity trajectories between islands, suggesting that differences in species richness trajectories across islands observed in Fig. $2 b$ can be attributable to the presence of the highland fauna on Hispaniola. Definitions of lines, shaded regions, and points are the same as in Fig. 2. Note that both panels depict models with linear and quadratic effects of elevation and full interactions with island identify though only the effect of elevation was significant after backwards model selection for lowland species richness. 